\title{
A Game Analysis on the Government Function in the Process of Vocational Education Group School-running
}

\author{
Ying Zhang \\ Jinsi Wang \\ Bo Chen \\ Hubei Communication Technical College Hubei Communication Technical College \\ Wuhan, China \\ Wuhan, China \\ zy20010110@hotmail.com \\ jsw-m@163.com \\ Hubei Public Security Department \\ Wuhan, China \\ babychen110@126.com
}

\begin{abstract}
Vocational education group school-running (VEGS) is a new trend of vocational education development. VEGS can help to allocate educational resources rationally and promote the development of vocational education rapidly. The experiences of VEGS development in foreign developed countries tell us that the government plays an important role in VEGS. However, few researching on the government functions in VEGS are offered in China. This paper analyzes the government functions in the process of VEGS with the game theory, and some suggestions are put forward.
\end{abstract}

Keywords- government; vocational education group; schoolrunning; game theory

\section{INTRODUCTION}

With the use and production of the knowledge and technology for manufacturing industry becoming important more and more, competence-based education has become a dominant trend in vocational education. Many countries develop vocational education by the means of vocational education group school-running (VEGS) [1]. VEGS is a school-running mode. Its core is one or several vocational educational organizations, which cooperate with industries and enterprises by specialty construction, personnel training, technology research and development, or some assets. VEGS plays a positive role in the reform and progress of vocational education. It can help to reach vocational educational resources sharing, strength school-enterprise cooperation, urban-rural cooperation and regional cooperation, and promote the colse integration of vocational education as well as. In the year to 2009, more than 200 vocational education groups were built in 25 provinces and cities in China. Additionally, more than 6000 institutions and 2000 schools participate in VEGS [2]. Nowadays, domestic and overseas researchers have payed attention to VEGS. Technical and vocational education and skills development are becoming increasingly important policy issues in developing countries [3]. By concluding forgien experiences of VEGS, Shi and Kuang (2009) pointed out the government plays an important role in VEGS in China. They presented the government plays four roles: (1) an investor to invest some projects/plans and purchase the achievement of education/training; (2) a disigner to allocate school-running resources and promote regional progress; (3) a coodinator to coodinate the profits among different alliance subjects; and (4) a supervisor to establish policies and measures[4]. Pen and Zhou (2009) put forword that the gorvernment should bring into play the roles, including advocation, orgnianzation, support, investment, and supervision [5]. Based on researching about the policies of VEGS, Hu (2011) pointed out that there are many problems in VEGS in China, such as too much interference, insufficent guiding, and lacking rational evaluation systems. She suggested that the government should fix the position rationally, creat a good enviroment, enhance a service wareness, optimize the school-running mechanism, introduce a competitive mechanism, and improve the supporting facility of VEGS gradually [6]. By the discusion of the problems in VEGS in Gansu, Tan (2012) proposed that the government should take a seires of measures, including reducing taxes, building incentive systems, and offering funds, to boost the developing of VEGS[2]. Although the views of these researchers provide some suggestions and references for the government to develop VEGS, the development of VEGS is a complex and dynamic process. This paper thinks the process includes at least two stages, including the initial stage and development stage. Then, when does the government take meassures? What measures does the government take? Which measure does the government take to reach the optimal social welfare? These problems are well worth studing. Accordingly, based on the game theory, this paper analyzes the influences of government functions on different stages of VEGS, and some suggestions are put forward.

The paper is organized as follows. Section2 introduces the hypothesis and description of model. Section 3 we turn our attention to analyze the government functions in VEGS with the game theory, and puts forward some suggestions. Finally, a discussion of the study's implications and the conclusions from this research drawn are in Section 4.

\section{HYPOTHESIS AND DESCRIPTION OF MODEL}

Vocational education group is the product of the development of market economy. It is not only the effective measure of school-enterprise cooperation, but also the exploration and practice of vocational educational school-running systems and modes. VEGS includes three types: school-school alliance, school-enterprise integration and combination education. Generally speaking, there is a high education level, good social reputation and rich educational resources school in the school-school alliance. In addition, the school is the leading of the school-school alliance. Moreover, there are many vocational educational schools with relevent fields that alliance with the leading school. To the school-enterprise integration, there are not 
only schools but also enterprises, which appaticipent to VEGS. Furthermore, the vocatioanl educational group is normally named by an enterprise's name. Finally, to the combination education of VEGS, the group is consisted of schools, enterprises, and other entities, which share resources to reach win-win. Accoding to the three types of VEGS, it shows that the essence of VEGS is the trans-organizational cooperation. With a view to facilitating research, this paper defines the subjects that paticipate to VEGS to be two groups. Furthermore, this paper analyzes on the government function in the process of VEGS.

Based on the Cobb-Douglas production function, the output of VEGS is:

$$
Q=A K^{a} L^{b}
$$

Here, the output of VEGS is Q; the output index of the investment by VEGS is $\mathrm{A}$, and $\mathrm{A}>0 ; \mathrm{K}$ and $\mathrm{L}$ are the two groups' inputs respectively, meanwhile $K \geq 0, L \geq 0$; and the influence factors of the two groups' inputs are a and b, respectively, meanwhile $a \geq 0, b \geq 0, a+b<1$.

The payoff functions of the two groups are:

$$
\begin{aligned}
& \pi_{1}=\lambda_{1} Q-K+\beta_{1} K \\
& \pi_{2}=\lambda_{2} Q-L+\beta_{2} L
\end{aligned}
$$

Here, the margina revenues of the two groups are $\lambda_{1}$ and $\lambda_{2}$ respectively, meanwhile $\lambda_{1}>0, \lambda_{2}>0$; and the indexes of the government inputs in the two groups are $\beta_{1}$ and $\beta_{2}$, respectively.

The government is on behalf of the interests of the society, and its purpose is to achieve the maximization of social welfare. To the government, social welfare is the difference between the revenues of the two groups and the government inputs:

$$
\omega=\left(\lambda_{1}+\lambda_{2}\right) Q-K-L
$$

\section{GAME ANALSIS}

Since the 1960s, vocational educational groups emerged in foreign countries. However, vocational educational groups arised in China until the 1990s. In the middle of 1990s, vocational educational groups were springing up gradually [2]. Based on historic events of Chinese vocational education, $\mathrm{Yu}$ (2009) pointed out that the development course of China's VEGS includes four stages: initial stages; spontaneous construction stage; coordinative management stage; and positive development stage [7]. Liu and Liu (2012) thought the process of VEGS is consisted of experimental stage; spontaneous form stage; scale expand stage; and rapid expansion stage [8]. Overall, the research thinks that the process of VEGS is divided into early stage and development stage.

\section{A. Early Stage}

- Nash game

After the government established series of encouraging VEGS policies, the two groups participate in VEGS. Their inputs were based on maximizing their outputs. With Nash equilibrium of game theory, this study analyzes the government functions in VEGS.

Under the encouraging VEGS policies, the two groups maximize their profits.

$$
\begin{aligned}
& \frac{\partial \pi_{1}}{\partial K}=a \beta_{1} A K^{a-1} L^{b}-1+\lambda_{1}=0 \\
& \frac{\partial \pi_{1}}{\partial L}=a \beta_{2} A K^{a} L^{b-1}-1+\lambda_{2}=0
\end{aligned}
$$

According to Eq. (4), (5), and (6), when $\frac{\partial \max \omega}{\partial \beta_{1}}=0$, $\frac{\partial \max \omega}{\partial \beta_{2}}=0$, the government's optimal strategy is:

$$
\begin{aligned}
& \beta_{1}^{1}=\frac{\lambda_{2}}{\lambda_{1}+\lambda_{2}} \\
& \beta_{2}^{1}=\frac{\lambda_{1}}{\lambda_{1}+\lambda_{2}}
\end{aligned}
$$

Based on Eq. (1) and (2), the groups' marginal revenues influence the government' inputs under the condition of Nash equilibrium. A side's index of the government investment will decrease if the other side's proportion of margianl revenues in total margianl revenues increases. Thus, for gaining higher investment, both sides will reduce their proportions of margianl revenues in total revenues. Finally, the Nash game leads both sides to be an equilibrium status, and the side with lower marginal revenues will gain more investment by the government.

- Stackelberg game

According to the types of VEGS, the strenth of multiple groups in VEGS are different. Generally speaking, a side is a leader while other sides are followers. The leading side maximizes its marginal revenues based on the government investment. Then, the following sides determine their inputs in accordence with the leading side's input. In view of the above, with Stackelberg equilibrium of game theory, this study analyzes the government functions in VEGS.

In the dynamic game process, after the government established the investment polices, the leading side 
determines its input. When $\frac{\partial \pi}{\partial L}=0$, the leading side's input is:

$$
L=\left(\frac{1-\beta_{2}}{b \lambda_{2} A}\right)^{\frac{1}{b-1}} K^{\frac{a}{1-b}}
$$

Then, the following side determines its optimal input. Based on Eq. (2) and (11), when $\frac{\partial \pi}{\partial K}=0$, its optimal input is:

$$
K=A^{\frac{1}{1-a-b}}(1-b)^{\frac{b-1}{1-a-b}}\left(\frac{a \lambda_{1}}{1-\beta_{1}}\right)^{\frac{1-b}{1-a-b}}\left(\frac{b \lambda_{2}}{1-\beta_{2}}\right)^{\frac{b}{1-a-b}}
$$

According to Eq. (9) and (10), when $\frac{\partial \max \omega}{\partial \beta_{1}}=0$, $\frac{\partial \max \omega}{\partial \beta_{2}}=0$, the government's optimal strategy is:

$$
\begin{gathered}
\beta_{1}^{2}=1-\frac{\lambda_{1}}{(1-b)\left(\lambda_{1}+\lambda_{2}\right)} \\
\beta_{2}^{2}=\frac{\lambda_{1}}{\lambda_{1}+\lambda_{2}}
\end{gathered}
$$

The Eq. (11) shows that the government's investment strategy is influenced with the leading side's marginal revenues $\lambda_{1}$ and the influence factor of following side's input. The government has selected an optimal investment strategy until it comprehensively evaluated the leading side's maximium profits and the following side's input abilities.

According to the Eq. (7) and (11), when $\frac{\lambda_{1}}{\lambda_{2}} \geq \frac{1-b}{b}$ and $\beta_{1}^{2} \leq 0$, the investment in Stackelberg leader is lower in Nash leader.

In accordence with the above, in early stage of VEGS, the government should take measures as follows:

(1) To the school-school alliance, the government should provide a good school running enviroment, guide elite schools to participant in VEGS, and make full use of the elite schools' education resources and brand advantages. Additionally, the government should increase the investment in weak schools, and absorb them to participant in VEGS by the merger \& recombination. As a result, the government helps to integrates education resources effectively, and VEGS forms scale.
(2) To the school-enterprise integration, if a school is a leader, the government should invest more in the enterprise than in the school, and establish some tax reduction policies on enterprises who participant in VEGS; if a enterprise is a leader, the government should invest more in the school than in the enterprise, and encourage the school to give full play to its advanteges; and if the integration between a elite school and a famous enterprise, the government should help them to set up a plantform to strenthen their cooperation in VEGS.

(3) To the combination education, the government should rationally evaluate both sides' school-running abilities, and invest more in the weak side than the other side. Additionally, if a side is a leader, the government should not offer funds to the side directly but construct a good soft enviroment, such as advocating vocational education, establishing risk safeguard mechanisms, and setting up international communicational plants.

\section{B. Development Stage}

At the stage, VEGS has begun to take shape. Both groups are a whole, and they try their best to seek for revenues maximization together. Moreover, they allocate their revenues in term of the pecentage and limited coditions in their agreement. Thus, with cooperation equilibrium of game theory, this study analyzes the government functions in VEGS.

According to the Eq. (2) and (3), the total profit function of both sides is:

$$
\max \pi=\left(\rho_{1}+\rho_{2}\right) Q-K\left(1-\delta_{1}\right)-L\left(1-\delta_{2}\right)
$$

Based on the Eq. (4) and (13), when $\frac{\partial \max \omega}{\partial \beta_{1}}=0$, $\frac{\partial \max \omega}{\partial \beta_{2}}=0$, the government's optimal strategy is:

$$
\beta_{1}^{3}=\beta_{2}^{3}=0
$$

The Eq. (14) shows that the support policies of government have little functions in VEGS at the development stage. It is because of their capital and experience accumulated, each group to form a whole, and their school running strengthened. As a result, the government should bring into play the orientation role of market mechanism, strive to creat a good enviroment of VEGS, and enable smooth running of VEGS.

\section{CONCLUSION}

With the rapid developing of vocational education, understanding the government functions in VEGS can help to promote the development of VEGS, harmonious develop between vocational education and regional economy, and support the reform, innovation, and evoluation of VEGS in theory. In this study, VEGS is consisted of early stage and development stage. With the 
game theory, it analyzed the government functions in the diffeent stages of VEGS, and put forward countermeasures and suggestions based on the three types VEGS. At the early stage of VEGS, the government polices can directly promote the development of VEGS. The government should establish feasible motivation policies to push forward the development of VEGS. However, at the development stage, the government cann't directly promote the development of VEGS. The government should give way to the market, and play the orientation role of market mechanism.

There are several limitations in this study, and it is at the same time open a wide spectrum of research opportunities. Firstly, this research was designed for China's VEGS and revealed the government functions in VEGS. Therefore, the results concerning the government functions are limited to China's VEGS. Secondly, the study only selected two groups as participation subjects in VEGS. Nevertheless, there may be many groups participate in VEGS. Furthermore, the research the research design used few parameters to define the VEGS. However, the development of VEGS is a complex and dynamic process, and there are many parameters. Therefore, these problems need to research and discuss deeply.

\section{REFERENCES}

[1] M. Brockmann, L. Clarke, P. Mehaut, C.Winch, “Competence-based vocational education and training (VET): the cases of England and France in a European Perspective, "Vocations and Learning, vol. 1, 2008, pp. 227-244.

[2] T. Tiejun, "Research on the government guide mechanis in the process of vocational education group school-running," Journal of Educational of Jilin Province, Vol. 28, Jul. 2012, pp. 28-29.

[3] K. King, "Education, skills, sustainability and growth: complex relations, ” International Journal for Educational Development, vol. 29, 2009, pp. 175-181.

[4] S. Weipin, K. Yin, "The basic experiences and enlightenment of foreign vocational education collectivization, " Chinese Vocational and Technical Education, May. 2009, pp. 25-31.

[5] P. Xinyu, Z. Qunfen, "An analysis on the government function in vocational education group school-running, " Forum on Contemporary Education, Oct. 2009, pp.116-117.

[6] H. Yinqin, "Thinking on vocational education group school-running policy and system security," Chinese Vocational and Technical Education, Sep. 2011, pp. 25-31.

[7] Y. Xiuqin, "the connotation and development of vocational education group school-running ," Chinese Vocational and Technical Education, Jun. 2008, pp. 15-17.

[8] L. Ming-ce, L. Zhibing, "Brief Analysis of Vocational Education Group's Developing process in China,” Career Horizon, vol. 8, Jul, 2012, pp. 23-28. 